\title{
Comparative Study on Drying Characteristics of Sewage Sludge in Two Kinds of Indirect Heat Drying Equipment
}

\author{
Jie-liang CHEN \\ State Key Laboratory of Clean Energy Utilization, \\ Institute for Thermal Power Engineering, Zhejiang \\ University, Hangzhou, China \\ E-mail: 13116793075@163.com
}

\section{Wen-di CHEN}

State Key Laboratory of Clean Energy Utilization, Institute for Thermal Power Engineering, Zhejiang

University, Hangzhou, China

E-mail: chen-wd@zju.edu.cn

\section{Fei WANG*}

State Key Laboratory of Clean Energy Utilization, Institute for Thermal Power Engineering, Zhejiang University, Hangzhou, China

E-mail: wangfei@zju.edu.cn

\author{
Zhen DENG \\ Hangzhou Construction and Development \\ Center of Water treatment facilities, \\ Hangzhou, China \\ E-mail: 447496015@qq.com
}

\section{Lu-kai LYU}

State Key Laboratory of Clean Energy Utilization, Institute for Thermal Power Engineering, Zhejiang

University, Hangzhou, China

E-mail: wjj521@stu.xjtu.edu.cn

\begin{abstract}
Sludge samples are taken from Qige Waste Water Treatment Plant in Hangzhou. The drying characteristics of sludge are determined by self-made small batch type drying machine. The paddle dryer and disc dryer are used in the drying tests to explore the effect of blade form on the sludge drying viscosity zone. Different heat source temperature and drying machine speed are set up for the same kind of drying machine to research on the effect of working conditions on the drying characteristics of sewage sludge. It is discovered that the paddle dryer has a better ability to overcome the sludge viscosity zone. High speed and drying temperature can speed up the sludge drying and improve the dry deterioration in the sludge viscosity zone. But it is necessary to consider the factors of equipment stability and safe operation at the same time.
\end{abstract}

Keywords- sludge thermal drying; paddle; disc; viscosity zone; drying characteristics

\section{INTRODUCTION}

With the development of industry and urbanization in China, capacity of urban industrial sewage and domestic sewage is increasing rapidly. Sludge is a solid waste which comes from the process of waste water treatment and the production of sewage sludge is also increasing at the same time. According to the principle of reduction, harmlessness and resource utilization of sludge treatment and disposal, resource utilization after heat drying is an ideal way for sludge attracting the attentions of scholars. However, the viscosity of sludge is a problem [1-5] during the drying process which needs to be solved for the development of sludge drying equipment. The operation conditions also have a great influence on the drying characteristics of sludge.

Currently, researches have done a lot of works on sludge drying process [6-7]. Qian [8] did the isothermal drying experiments about the thickness of different sludge layers and species by using the air blowing oven at $40 \sim 160^{\circ} \mathrm{C}$ and modeled the drying dynamics of sludge. The result shows that drying rate becomes bigger when drying temperature is high and thickness is thin. Zhang [9] found that the content of bound water in sludge had a certain positive correlation with the increasing consumption of thermal drying energy. Reducing the content of bound water will contribute to decreasing the consumption of the sludge thermal drying. Wang [10] has researched on the basic characteristics of the sludge such as the heat transfer, mass transfer and viscosity during the sludge drying process. It is showed that when the sludge was in the larger thermal conductivity, faster mass transfer rate and smaller viscosity, the efficiency of the drying process was high and the dry power requirement was small.

In this paper, the drying characteristics of sludge were measured by lab-scale batch sludge dryers. Sludge samples are from the Qige Waste Water Treatment Plant in Hangzhou. Paddle dryer and disc dryer are used in drying experiment to find out the influences of dryer blade form on the viscosity zone. The effects of operation condition on the sludge drying characteristics were investigated by setting the different temperature and rotation speed for the same dryer. 


\section{MATERIALS AND METHODS}

\section{A. Sludge Sample}

The sludge samples are taken from Qige Waste Water Treatment Plant in Hangzhou. The water content of sewage was measured by national standard method of gravimetric determination and the average value was $81.14 \%$.

The results of the sludge analysis were showed in Table 1 in accordance with the national standard for the proximate, ultimate, heat value analysis.

TABLE 1. PROXIMATE, ULTIMATE AND HEAT VALUE ANALYSIS OF SLUDGE SAMPLES

\begin{tabular}{cccccccccc}
\hline & \multicolumn{3}{c}{ Proximate Analysis } & \multicolumn{4}{c}{ Ultimate Analysis } & \multicolumn{2}{c}{$\begin{array}{c}\text { Heat Value } \\
\text { Analysis }\end{array}$} \\
\hline $\mathrm{M}_{\mathrm{ad}} \%$ & $\mathrm{~A}_{\mathrm{ad}} \%$ & $\mathrm{~V}_{\mathrm{ad}} \%$ & $\mathrm{FC}_{\mathrm{ad}} \%$ & $\mathrm{C}_{\mathrm{ad}} \%$ & $\mathrm{H}_{\mathrm{ad}} \%$ & $\mathrm{~N}_{\mathrm{ad}} \%$ & $\mathrm{St}, \mathrm{ad} \%$ & $\mathrm{O}_{\mathrm{ad}} \%$ & $\mathrm{Q}_{\mathrm{b}, \mathrm{ad}}(\mathrm{kJ} / \mathrm{kg})$ \\
2.93 & 54.98 & 37.98 & 4.11 & 22.02 & 3.54 & 3.21 & 0.77 & 12.55 & 9998.00 \\
\hline
\end{tabular}

\section{B. Experimental Set-Up of the Sludge Dryer}

Figure 1 shows the experimental set-up of the sludge, a lab-scale batch paddle dryer is used in the set-up. It consists of one jacket trough, one hollow shaft and several wedgeshaped paddles. The rotational speed is controlled by the governor. Heat conducting oil in the tank is heated by the heat rod with electricity. The temperature of the conducting oil is controlled by temperature controller. The heated conducting oil is sent to the jacket trough, hollow shaft and paddles by the oil pump. During the drying process, the pump provides the dryer with the fresh air and makes sure that dryer is working under the negative pressure operation. Water vapor produced during the process of drying passes through the condenser with air and the condensate was collected by the conical flask put on the electronic balance.

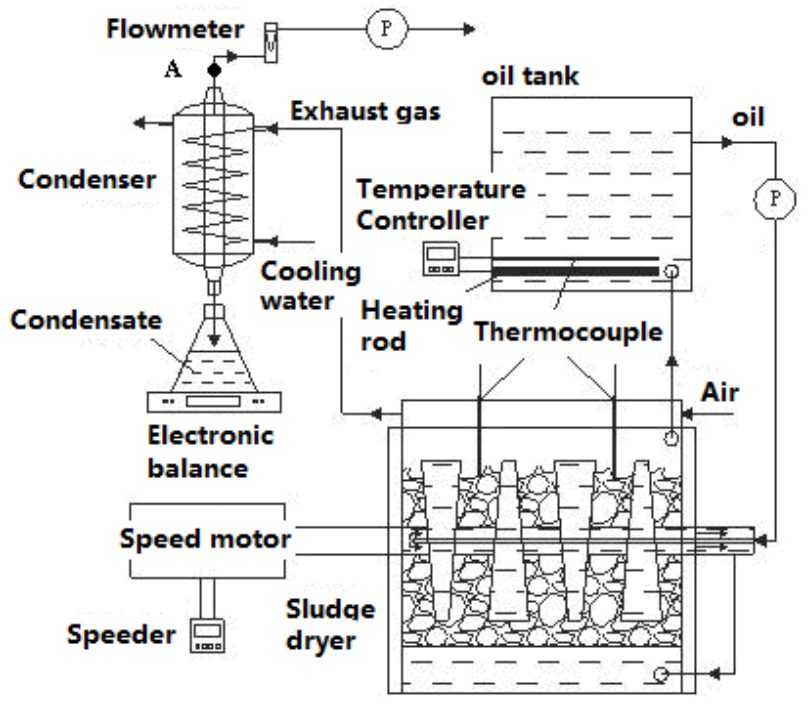

Figure 1. Test system of sludge thermal drying

\section{Operation Conditions of the Drying Experiment}

Two kinds of lab-scale batch dryer disc dryer and paddle dryer are used in the experiment to test the sludge viscosity and research the influences of the drying way, drying temperature and the speed of the stirrer on the viscosity zone. The operation condition is showed in Table 2.

TABLE 2. TEST CONDITION

\begin{tabular}{|c|c|c|c|c|c|c|c|c|c|c|}
\hline \multirow{2}{*}{$\begin{array}{l}\text { Typer of Dryer } \\
\text { Temperature }\end{array}$} & \multicolumn{5}{|c|}{ Disc Dryer } & \multicolumn{5}{|c|}{ Paddle Dryer } \\
\hline & $180^{\circ} \mathrm{C}$ & $160^{\circ} \mathrm{C}$ & $140^{\circ} \mathrm{C}$ & $160^{\circ} \mathrm{C}$ & $160^{\circ} \mathrm{C}$ & $180^{\circ} \mathrm{C}$ & $160^{\circ} \mathrm{C}$ & $140^{\circ} \mathrm{C}$ & $160^{\circ} \mathrm{C}$ & $160^{\circ} \mathrm{C}$ \\
\hline $\begin{array}{c}\text { Speed of } \\
\text { Stirrer }\end{array}$ & 5 & 5 & 5 & 10 & 20 & 5 & 5 & 5 & 10 & 20 \\
\hline
\end{tabular}

\section{RESULTS AND DISCUSSION}

\section{A. Drying Characteristics of Disc Dryer}

The characteristics comparison of the disc dryer in different temperature is showed in Figure 2. The curvature of the two drying rate curves comes from 140 and $160^{\circ} \mathrm{C}$ respectively is similar while the drying rate is significantly improved when the dryer wall temperature reaches to $180^{\circ} \mathrm{C}$. During the drying process, the wall temperature became higher which resulted in the greater temperature difference between the heat transfer surface and sludge layer because of the stability of the temperature. The heat flux is greater resulting in the stronger water evaporation capability. On the one hand, the higher dryer wall temperature is, the greater the fluctuation of sludge drying rate is. On the other hand, 
the dryer wall temperature has little influence on the sludge and steam temperature which maintains around $90 \sim 95^{\circ} \mathrm{C}$ and $80^{\circ} \mathrm{C}$ respectively.

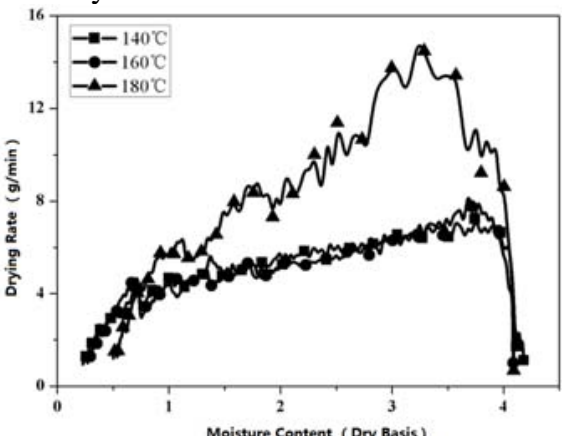

(a) drying rate

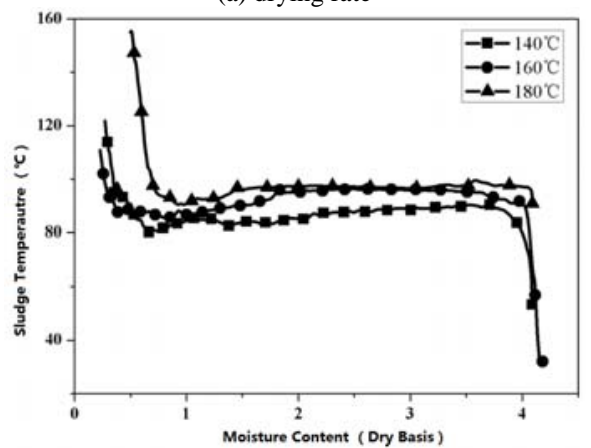

(b) sludge temperature

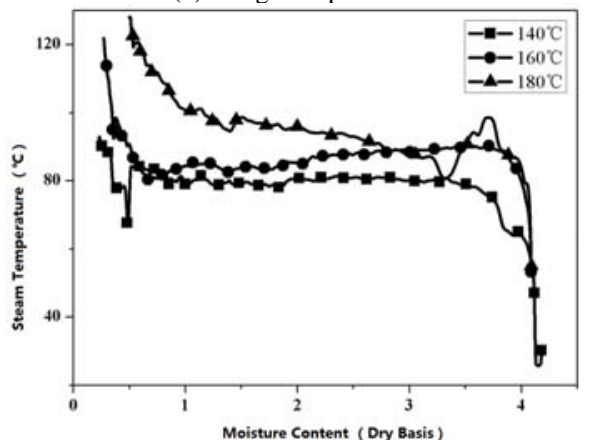

(c) steam temperature

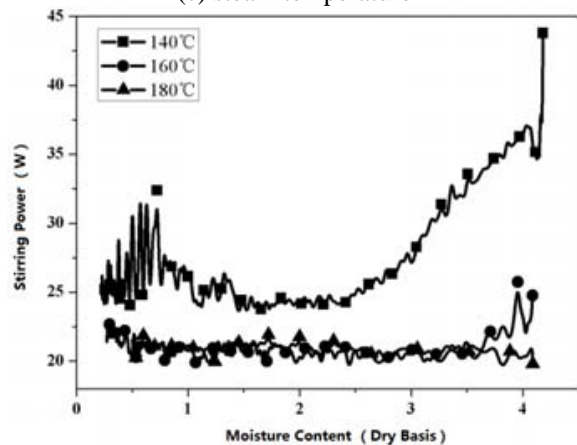

(d) stirring power

Figure 2. Drying characteristic curves of sludge disc dryer with differen heating temperature

The characteristics comparison of the disc dryer in different speed of stirrer is showed in Figure 3. The speed of the stirrer has little influence on the drying rate for the disc dryer. The experiment shows that increasing the speed of stirrer is not the effective way to improve the drying rate in the viscosity zone for the stable distance between paddle and the blade. Besides, the speed of stirrer also has little influence on the sludge and steam temperature. However, the stirring power is greater with the increasing of the speed for the disc dryer in the high moisture content zone because it is the blade clean the disc surface. Then for the stable distance between blade and disc, when the thickness of the sludge adhere to the disc is less than the length between disc and blade, it is hard for blade to clean which produce the resistance against the rotation of the disc. Above all, it results the increasing in torque and the stirring power.

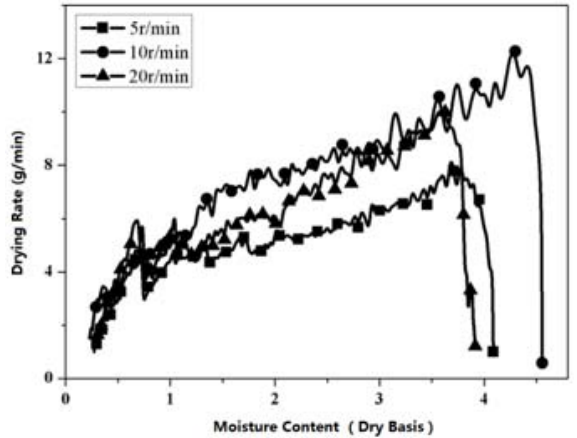

(a) drying rate

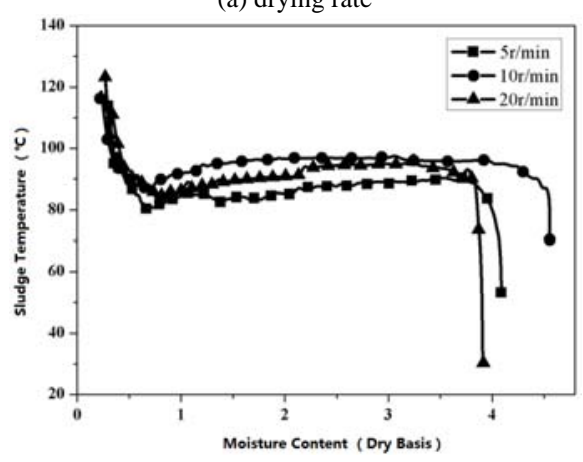

(b) sludge temperature

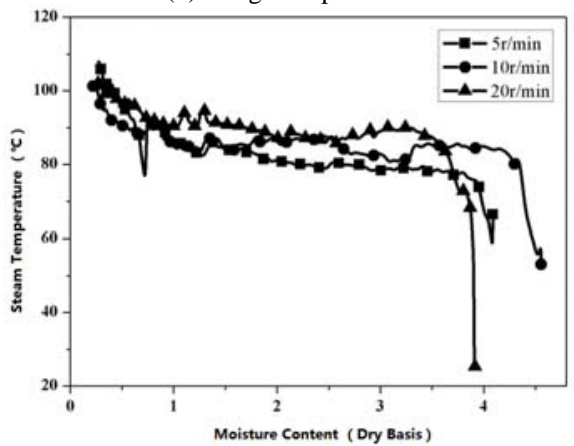

(c) steam temperature 


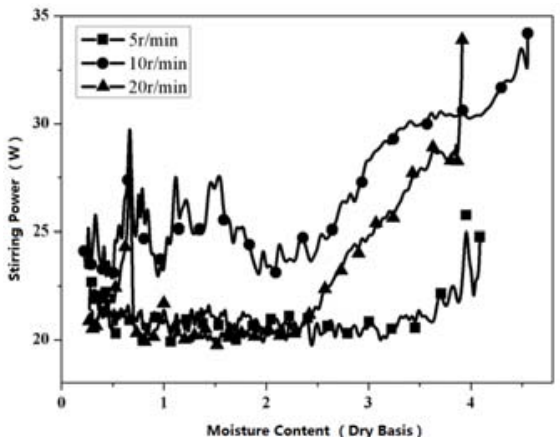

(d) stirring power

Figure 3. Drying characteristic curves of sludge disc dryer with different rotation rate

\section{B. Drying Characteristics of Paddle Dryer}

The drying characteristics comparison of paddle dryer in different drying temperature is showed in Figure 4. The experiments show that the higher the dryer wall temperature is, the greater the sludge drying rate is. Compared with the disc dryer, the fluctuation of the drying rate is less for the paddle dryer stir more evenly resulting in less influence on the drying rate by the inner water mass transfer efficiency. In addition, dryer wall temperature has little influence on the temperature of the sludge layers because of the peeling and crushing of the sludge by paddles. Specifically, when the inner sludge exposures, the water on the surface of the sludge evaporates rapidly resulting in the decline of the sludge temperature. Besides, dryer wall temperature has little influence on steam temperature, which is kept around $80^{\circ} \mathrm{C}$. The higher the dryer wall temperature is, the lower the stirring power is. Higher dryer wall temperature can reduce the viscosity making it more easily to be peeled, crushed and stirred.

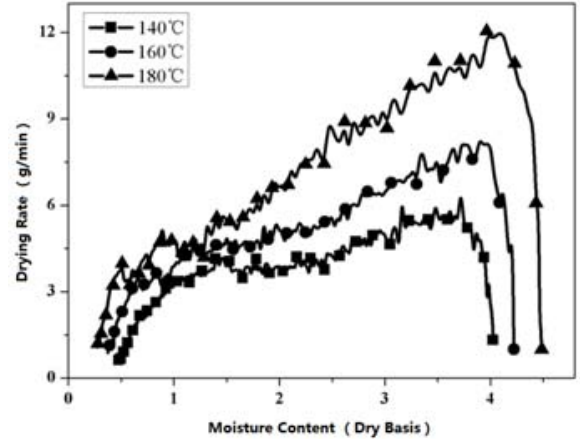

(a) drying rate

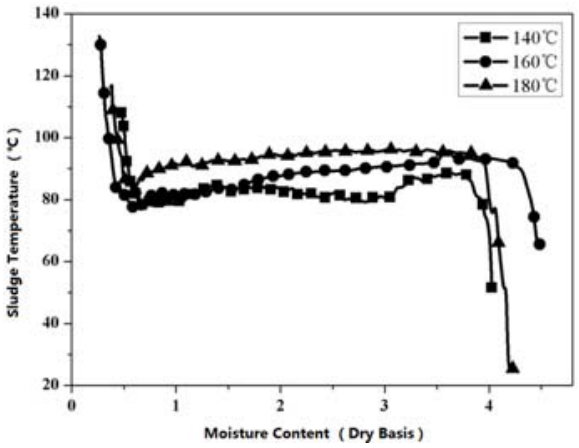

(b) sludge temperature

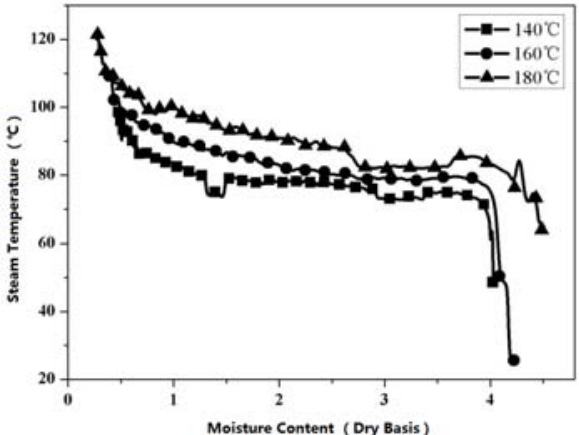

(c) steam temperature

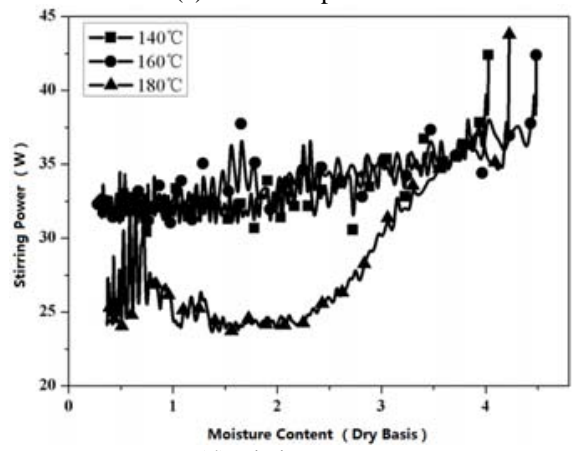

(d) stirring power

Figure 4. Drying characteristic curves of sludge paddle dryer with different heating temperature

The characteristics comparison of the paddle dryer in different stirring speed is showed in Figure 5. For the paddle dryer, when the rotational rate become faster, the fluctuation of the sludge and steam temperature is greater for the good mixing performance of paddle dryer making the exchange between the sludge at temperature point and others. The stirring speed increases with the drying rate while it has little influence on the drying rate. It means that the stirring performance of the paddle dryer is better than that of disc dryer. Compared with the disc dryer, the fluctuation of the stirring power in paddle dryer is less for the rotation in opposite direction of the intermeshed paddles in the paddle dryer. Moreover, the wedge structure of the paddles make the distance between neighboring paddles cyclical change. It is advantageous for peeling the sludge layers, crushing and stirring sludge clumps. 


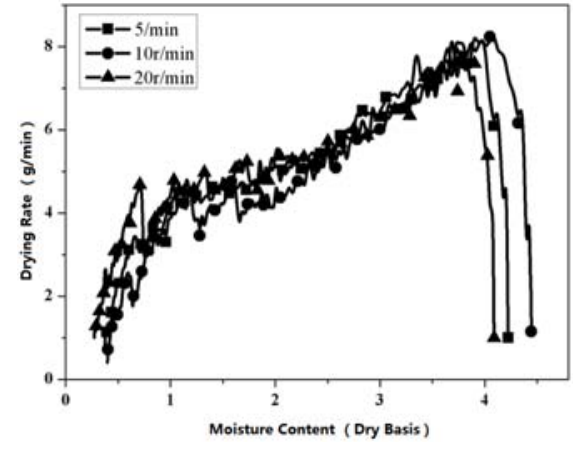

(a) drying rate

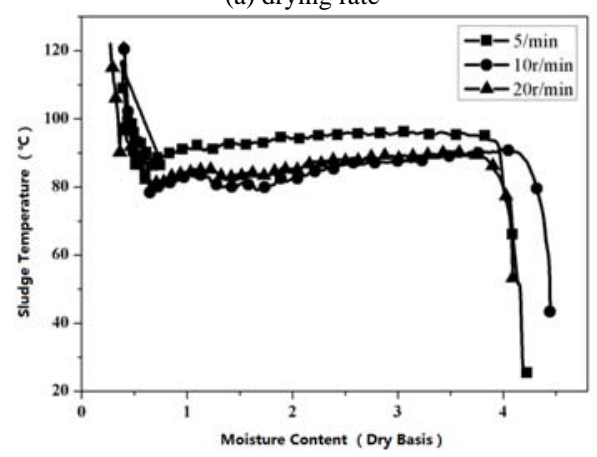

(b) sludge temperature

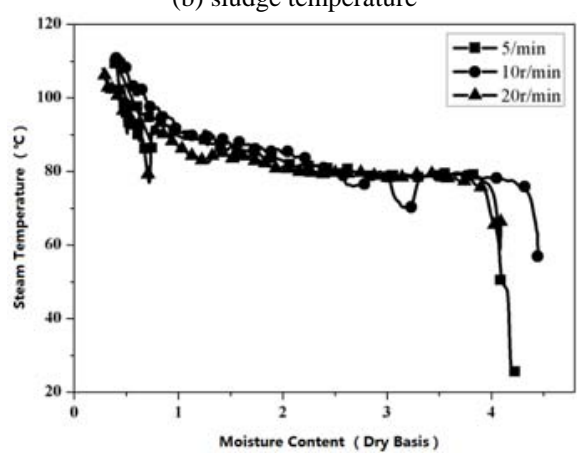

(c) steam temperature

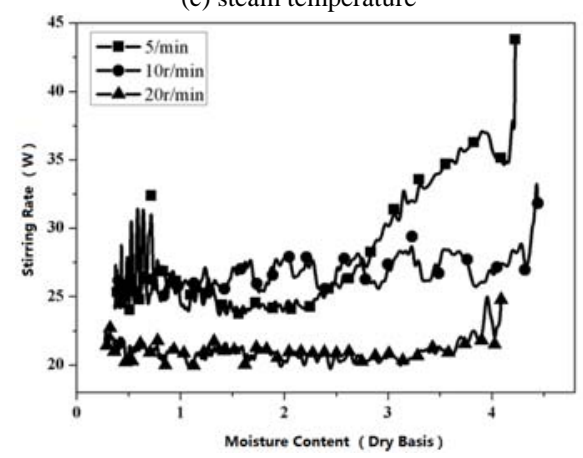

(d) stirring power

Figure 5. Drying characteristic curves of sludge paddle dryer with different rotation rate

\section{CONCLUSIONS}

The sludge samples are taken from Qige Waste Water Treatment Plant in Hangzhou. The research measures the drying characteristics of sludge by the lab-scale self-made paddle and disc dryer. The experiments show the influences on the drying characteristics by setting different operation conditions.

The processes are different for the different types of dryer machine. The experiments show in the paddle dryer, the stirring power is less in the viscous zone compared with other areas meaning the paddle dryer has the better ability to overcome the viscosity compared with the disc dryer.

In the research, the experiments are carried out with different temperature and rotational speed of the dryer when test the viscous zone. It can be concluded that the drying rate is high and the viscous area is small at high heating temperature. In addition, it keeps the high evaporation rate and the power output is stable with little fluctuation. When sludge is in the viscous area and keeps the state for a long time, the drying rate slows down obviously. The higher speed of mixing has a greater help for the sludge mixing and it can overcome the influence of the viscosity. However, the fluctuation become obvious which is not beneficial to the stability of the drying system.

\section{REFERENCES}

[1] Study on Efficient Sludge Drying Method and Optimal Energy Efficiency of Sludge Drying-Incineration Combined System[D]. Zheng Jiang University, 2014.

[2] Zhao Peitao, Mou Zhanjie, Zhang Changfei. Experimental Study on the characteristics of Drying Viscous Zone of Rotating Heat Conduction Sludge[J]. Chemical Equipment Technology, 2010, 01:8$10+14$.

[3] Zou Daoan, Huang Jin, Bai Hailong. Experimental Research on Thermal Drying and Combustion Characteristics of Sludge[J]. Environment Pollution \& Control, 2012, 04 :5-10.

[4] Hao Xianpeng. Research Advances in Sludge Thermal Drying[J]. Sichuan Chemical Industry, 2015, 05:11-13.

[5] M. Milhe , C. Charlou, M. Sauceau, and P. Arlabosse. Modeling of Sewage Sludge Flow in a Continuous Paddle Dryer[J]. Drying Technology, 2014, 33:9, 1061-1067.

[6] Shaoqing Chen, Fei Wang,et al. Experimental and Theoretical Research on Agitated Contact Drying of Sewage Sludge in aContinuous Paddle Dryer. Drying Technology. 2016,

[7] Wang Ruikun, Liu Jianzhong, Yu Yujie. Characteristics and Drying Technology of Municipal sludge[J]. Water \& Wastewater Engineering, 2010, S1:153-158.

[8] Qian Wei. Investigation on the Drying Characteristics and Combustion Treatment of Sludge[D]. South China University of Technology, 2014.

[9] Zhang Weijun. Study on the Municipal Sewage Sludge Thermal Drying Characteristics and Energy Consumption[D]. Chongqing University, 2009.

[10] Wang Rui. Study on Basic Characteristics of Sludge During Its Drying Process and Sludge Drying Technology[D]. Shen Yang Institute of Aeronautical Engineering, 2010. 